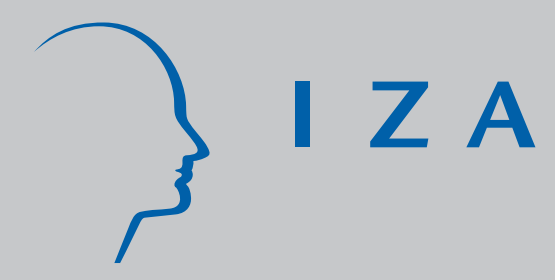

IZA DP No. 1634

\title{
A Multinomial Logit Model of College Stopout and Dropout Behavior
}

Leslie S. Stratton

Dennis M. O'Toole

J ames N. Wetzel

J une 2005 


\title{
A Multinomial Logit Model of College Stopout and Dropout Behavior
}

\author{
Leslie S. Stratton \\ Virginia Commonwealth University, CIM \\ and IZA Bonn \\ Dennis M. O'Toole \\ Virginia Commonwealth University \\ James N. Wetzel \\ Virginia Commonwealth University
}

Discussion Paper No. 1634

June 2005

IZA
P.O. Box 7240
53072 Bonn
Germany

Phone: +49-228-3894-0

Fax: +49-228-3894-180

Email: iza@iza.org

\begin{abstract}
Any opinions expressed here are those of the author(s) and not those of the institute. Research disseminated by IZA may include views on policy, but the institute itself takes no institutional policy positions.
\end{abstract}

The Institute for the Study of Labor (IZA) in Bonn is a local and virtual international research center and a place of communication between science, politics and business. IZA is an independent nonprofit company supported by Deutsche Post World Net. The center is associated with the University of Bonn and offers a stimulating research environment through its research networks, research support, and visitors and doctoral programs. IZA engages in (i) original and internationally competitive research in all fields of labor economics, (ii) development of policy concepts, and (iii) dissemination of research results and concepts to the interested public.

IZA Discussion Papers often represent preliminary work and are circulated to encourage discussion. Citation of such a paper should account for its provisional character. A revised version may be available directly from the author. 
IZA Discussion Paper No. 1634

June 2005

\section{ABSTRACT \\ A Multinomial Logit Model of College Stopout and Dropout Behavior}

Studies of college attrition typically assume that all attrition is permanent. We use data from the 1990/94 Beginning Postsecondary Survey to distinguish between long-term dropout and short-term stopout behavior in order to test that assumption. We find significant differences between those who stop out and those who drop out in the first year. Failure to recognize these differences biases the results of standard attrition models and hence may cause policy makers to pursue inappropriate policy initiatives or incorrectly target at-risk populations. Furthermore, the type of financial aid received is found to have a differential impact on stopout versus dropout probabilities.

JEL Classification: $\quad 121$

Keywords: college persistence, college dropout

Corresponding author:

Leslie S. Stratton

Department of Economics

Virginia Commonwealth University

1015 Floyd Ave.

P.O. Box 844000

Richmond, VA 23284-4000

USA

Email: Isstratt@vcu.edu 
Introduction

College attrition rates are of substantial concern to policy makers entrusted with investing taxpayers’ money as well as to economists interested in educational attainment and earnings opportunities. Studies indicate that about half of all students who enter postsecondary education fail to complete any postsecondary credential within five years (Brawer 1996). However, about two-thirds of first-year persisters do complete their degree (Horn 1998). Thus, completion of the first year and enrollment in the second year appears to have a significant impact on long-term persistence and the likelihood of obtaining a degree. At the same time, there is a growing body of evidence indicating that a substantial fraction of students who withdraw during their first year actually return to some institution of higher education shortly thereafter. By failing to distinguish between dropouts and stopouts (more permanent versus less permanent withdrawals), researchers may incorrectly identify the factors associated with true dropout behavior. If 'standard' attrition studies have been used to design policy responses to reduce attrition, these policy responses may be inappropriately targeted. Students who stop out may not need explicit intervention programs or may need different types of assistance relative to students who drop out. Our goal is to determine whether the factors associated with stopout behavior are statistically different from the factors associated with dropout behavior and to ascertain whether treating these two groups as one may lead to misleading statistical results and thus to inaccurate targeting of the population truly at-risk for dropping out.

To distinguish between short-term stopout and long-term dropout behavior, we use longitudinal data from the 1990 Beginning Postsecondary Survey. We focus on the first year of enrollment because this is the period during which most attrition occurs. In particular, we identify students who are enrolled continuously throughout their first year and begin their second 
year of college (individuals henceforth designated as having 'continuous enrollment'), students who withdraw by the start of their second year and are not observed returning for over a year ('dropouts'), and students who withdraw by the start of their second year but return within one year ('stopouts').

We use a multinomial logit specification to model the choice amongst these three outcomes. This specification allows us to test whether the factors associated with stopout behavior are statistically different from the factors associated with dropout behavior. If the factors affecting dropout and stopout behavior are similar, then a simple logit specification may be appropriate. If the factors are different, then the approach used here will provide a more accurate picture of first year enrollment patterns.

\section{Literature Review}

Educational researchers have long recognized that not all students who initially enroll in college persist till they receive a degree. There exists a substantial literature, both theoretical and empirical, that seeks to identify the factors associated with attrition. Three of the most comprehensive theoretical models are Tinto’s Student Integration Model (1975), Bean’s Student Attrition Model (1980), and the College Choice Nexus Model (St. John et al. 2000).

The Student Integration Model attributes persistence to a high degree of congruence between students and institutions. According to this theory, student's entry characteristics (family background, family socioeconomic status, and parental educational level, as well as individual academic ability, race, and gender) directly influence the student's commitment first, to the goal of college graduation and second, to a particular institution. An excellent review of Tinto’s approach and the many empirical studies testing Tinto’s model was conducted by 
Braxton, Sullivan, and Johnson (1997). They find mixed support for Tinto’s model. One particular critique is that Tinto's theory fails to incorporate factors external to the institutional environment (Cabrera et al. 1992).

Bean's Student Attrition Model is more comprehensive in that it explicitly incorporates external factors. Bean's theory stresses the importance of behavioral intentions (whether the student intends to stay or leave) as predictors of persistence (Bean 1980). Tests of this model have supported the role of organizational, personal and environmental variables in shaping attitudes and intentions to persist or to withdraw (Cabrera et al. 1992). In a study comparing Tinto's model with Bean's model, Cabrera et al. (1992) found that the two models were not mutually exclusive and that the external factors highlighted in Bean's model were highly important in explaining persistence, especially factors such as encouragement from parents and friends, and financial support from parents.

A third model of persistence, known as the College Choice Nexus Model, posits that there is a connection between a student's college choice and that student's subsequent persistence in college. The College Choice Nexus Model hypothesizes that persistence is shaped through a three-stage process (St. John et al. 2000). In the first stage, socioeconomic factors as well as academic ability affect a student's predisposition to go to college. In the second stage, the student estimates the benefits and costs associated with enrollment at a particular institution. The third stage begins once the student enrolls in college. The collegiate experiences as well as academic performance shape the student's perceptions of the economic and non-economic benefits of staying in school and graduating from that institution. Financial aid positively affects persistence decisions by reducing the costs associated with obtaining a degree. Negative college experiences, such as poor grades, make the student more inclined to withdraw. Generally 
speaking, dropout behavior is explained as a rational response to new information that changes the probability with which one will receive a degree and/or the costs/benefits associated with that degree. Economics oriented articles in this line of research have focused on modeling and estimating the impact of uncertainty and sequential choice on the decision to persist (Manski 1989, Altonji 1993, Cameron and Heckman 1998).

Most of the attrition literature, however, assumes that the withdrawal decision is a permanent one; that once students stop enrolling, they never return. Much less attention has been paid to the phenomenon known as stopout behavior, wherein an individual who has begun college temporarily interrupts his/her college career. Many of the data sets used to analyze attrition report enrollment at only two points in time, usually initial enrollment and then either one term or one year later, and hence are not able to identify those students who reenter following that interruption. Others have samples with too few observations across individuals and/or time to permit analysis of such behavior (for example, Montmarquette, Mahseredjian, \& Houle 2001).

Yet stopout behavior is not unusual. O’Toole, Stratton, and Wetzel (2003) found that about 30 percent of all students actively pursuing an academic degree interrupt their education for at least one term during the five years following initial enrollment. Horn (1998) reports that almost 30\% of students enrolled (but not necessarily seeking a degree) in either four-year colleges or two-year public schools interrupt during their first year, but that almost half of these interruptions are relatively short-lived (less than five years). This suggests that half of all first year attrition is short-term in nature. She presents evidence that students who leave college before their second year and do not return for five years are older, are more likely to have children, and are more likely to work full time as compared to students who do return. Light 
(1996) also contributes to this attrition research by looking at a sample of students who have stopped enrolling and modeling the duration of their interruption. She finds that local unemployment rates and wage rates are significant determinants of student reenrollment. However, her analysis assumes that all interruptions are temporary and that, at some point, everyone will reenroll.

Modeling the Decisions to Drop Out and to Stop Out

We model enrollment choice using a random utilities model in which individuals face three choices: continuous enrollment (c), short-term stopout (s), and long-term dropout (d). The utilities associated with each of these choices are designated $U_{c}, U_{s}$, and $U_{d}$ respectively. This utility is modeled as a function of individual specific characteristics, $\mathrm{X}$, that effect the utility associated with each choice differently. Hence,

$$
\mathrm{U}_{\mathrm{ji}}=\mathrm{X}_{\mathrm{i}} \alpha_{\mathrm{j}}+\mathrm{e}_{\mathrm{ji}}
$$

where subscript $\mathrm{j}$ denotes the choice and subscript i denotes the individual. While we never observe utility, we can infer from the choices people make how they rank some of these alternatives. Thus, if an individual chooses to persist, it must be the case that $\mathrm{U}_{\mathrm{ci}}>\mathrm{U}_{\mathrm{si}}$ and $\mathrm{U}_{\mathrm{ci}}>$ $\mathrm{U}_{\mathrm{di}}$. If the $\mathrm{e}_{\mathrm{ji}}$ are distributed Weibull, the differences in the $\varepsilon$ are distributed logistic and a multinomial logit (henceforth MNL) can be used to estimate the differences in the parameters $\alpha$ (ie. $\alpha_{c}-\alpha_{s}$ and $\alpha_{c}-\alpha_{d}$ in the example) (Maddala 1994).

Given our interest in differentiating among the choices made during the critical first year following matriculation, the MNL model is well suited to our needs. An alternative approach would be to employ a duration model with a competing hazards specification that distinguishes between graduation, dropout, and stopout. This approach would be akin to DesJardin, Ahlburg, 
and McCall (2002) except for the added differentiation between dropouts and stopouts.

Estimation of such a model presents some classification issues. For example, we would have to define 'graduation' in a sample that includes students pursuing both an AA as well as a BA degree. It is not clear how those students seeking a BA degree who have completed the credits for an AA degree, but not those for a BA degree, should be classified. More importantly, a duration model would be useful if we were attempting to identify the timing as well as the type of departure, but our focus is on the choices individuals make during their first year following matriculation. Not only is this the critical period during which most attrition occurs, but by employing a MNL model focusing only on the first year we are better able to compare our results with prior research that uses a standard logit (SL) specification to examine first year attrition, but treats all withdrawals alike as permanent dropouts.

To proceed we need to identify the factors (the Xs) associated with each of the three possible enrollment outcomes. To do so, it is useful to consider the decision process students may employ when considering their future enrollment status. This analysis is contingent upon having decided to begin college in the first place. Theoretically, the decision to leave, whether temporarily or permanently, could have been planned prior to initial enrollment or it could be the result of revised expectations.

Since attending college is not free and the benefits attributable to less than a year of college are quite small, it seems unlikely that individuals would plan ex-ante to attend for only one or two terms and then permanently drop out. A more likely explanation for dropping out during the first year is revised expectations that follow from new information. One of the most important pieces of new or revised information for college students is their academic performance in their first year of college. While test scores or high school grades may provide 
some information on academic potential, actual first year college performance as measured by grades may be an even better indicator of the likelihood with which an individual will complete a program of study. Other information which may not be anticipated prior to enrollment relates to the impact of major life changes such as getting married or having a child. Changes in marital or parental status are likely to significantly affect one's household and financial responsibilities and one's opportunity cost of time. Such changes could easily cause students to reevaluate their decision to pursue a college degree.

The decision to stop out could also be the result of new information. New information relating to temporary changes in the opportunity cost of time may lead an individual to stop out. This includes new information about labor market conditions for those whose most valuable alternative activity is employment. New information about the time and effort required to study and receive reasonable grades may also lead an individual to reevaluate his/her potential to graduate at the current institution. Students with either low or high grades may decide to transfer and, while pursuing transfer opportunities, they may experience an interruption in their college experience of a term or even a year. Students with low grades may seek an easier institution; students with high grades may seek a better institution or may reapply to better institutions that initially turned then down.

Stopout behavior, however, could also have been anticipated ex-ante. Married individuals, individuals with children, and older individuals with work experience know they have a higher opportunity cost of time and may expect to have a more discontinuous enrollment path. Those planning to be married or to have a child may elect to enroll and plan to stop out for a period of time. Students who start with fewer economic resources may also plan to stop out, in order to replenish the financial resources with which to continue their education. Students with 
seasonal jobs may plan to enroll full-time for one term, then stopout to work full-time for the next term, repeating this pattern in subsequent years.

Thus, the determinants of dropout behavior may very well differ from the determinants of stopout behavior. If the determinants of the two behaviors are different, treating all individuals who interrupt their enrollment alike will yield biased estimates of the factors influencing true dropout behavior. Factors that significantly affect only one behavior pattern such as stopout (dropout) behavior but not dropout (stopout) behavior may not appear statistically significant when all withdrawals are treated identically. The bias will be even greater if there are cases where a factor is positively associated with one type of withdrawal and negatively associated with the other. Estimation of a MNL model will enable us both to allow for and to test for differences in the factors associated with each of the three outcomes: continuous, dropout, and stopout behavior.

Data

The data set we use is the 1990/94 Beginning Postsecondary Survey (BPS-90) developed by the National Center for Education Statistics (NCES). This survey interviews students who attend some type of postsecondary institution for the first time in the 1989-90 academic year. These individuals are reinterviewed regardless of their later enrollment status in both 1992 and 1994 to provide a data set which spans a five year time period.

Our focus on first-time college students pursuing an academic degree requires we impose some restrictions on this sample. First, we exclude non-degree seeking students. Next, we exclude enrollment at trade and technical/vocational schools as well as for-profit institutions. Credits at such schools rarely transfer to academic institutions. Furthermore, many programs of 
study at such institutions are designed to be completed within a year making analysis of second year enrollment inappropriate. These restrictions reduce our sample considerably from 7253 to 5471 individuals. Students who start an academic degree program at a community college are included. These students should be enrolled for a second year (whether at the community college or via transfer to a four-year institution) even if they are pursuing only an Associate degree.

Other individuals were excluded because follow-up interviews were not available or because they were not initially enrolled on a full-time basis. In the former case, we are unable to determine their enrollment status and in the latter case there is research suggesting that the determinants of attrition differ by initial part-time versus full-time enrollment status (Weiler and Pierro 1988). While an evaluation of part-time student behavior is clearly a subject of great policy interest and worthy of future research, combining both part-time and full-time students in a single data pool would raise substantial questions regarding the interpretation of the results. Our final sample constitutes 4226 individuals. ${ }^{1}$

We use this final sample to distinguish continuous first year enrollment from short-term stopout behavior from long-term dropout behavior. Ideally the random utilities model requires that we have information on each respondent's ex-ante intentions. In reality, we only observe ex-post revealed behavior. While classification errors of all sorts are possible, we believe that because students intending to stop out have to decide when to reenter, they are more likely to revise/change their decision than students pursuing other enrollment paths. If this is true, our reliance on ex-post revealed behavior will lead us to disproportionately misclassify those who expected to become stopouts as dropouts. However, that fact can be used to our advantage empirically. If our ability to distinguish between stopout and dropout intentions is imperfect, 
then the model should be biased against finding differences between stopout and dropout behavior and we will fail to reject the standard logit model that treats all withdrawals alike.

Using our longitudinal data, we define continuous enrollment as enrollment for three consecutive semesters or four consecutive quarters, depending upon the institution's calendar type. Thus, continuous enrollment means the student enrolls in the first term of their second year of college. Dropout behavior is defined as non-enrollment for a period of at least three semesters (four quarters). This long-term dropout behavior can commence at any time within the three semester/four quarter time frame used to define continuous enrollment, but no student classified as a dropout will be enrolled in the first term of their second year of college. Individuals are classified as stopouts if they leave but then return after no more than a one year absence. Thus, respondents who are enrolled for two semesters, not enrolled for two semesters, then enrolled again the following term would be classified as having stopped out because they interrupted their education, but returned within the three semester time frame. Some of these students will be enrolled during the first term of their second year of college; some will not.

This classification scheme does a good job capturing the conceptual differences between stopout and dropout behavior. We recognize, however, that the use of any fixed time frame introduces the possibility of classification error. First, some of those classified as having stopped out may actually enroll for only one term following reentry and then decide to leave permanently. These students might be more accurately classified as long-term dropouts. Of those classified here as stopouts, fewer than $15 \%$ are observed enrolled for only one term following their return to school. Second, some of those classified as dropouts might in fact be long term stopouts who reenter in the term or terms following the time period we use to distinguish between stopout and dropout behavior, and those individuals may be more accurately 
described as stopouts. In reality, over $75 \%$ of those classified here as dropouts are not observed enrolled again for as long as they are followed by the BPS and our basic results are robust to the reclassification of the $25 \%$ of dropouts who ever reenroll as temporary stopouts. Overall, for both the theoretical reasons discussed earlier and the empirical reasons discussed here, we believe that our classification scheme may overstate dropout relative to stopout behavior, but as stated earlier the noisier this classification the less likely we are to find evidence that stopout and dropout are distinct behaviors. Finally, there is also some concern that those classified as being continuously enrolled will drop out later. In fact, fewer than $3 \%$ of those classified here as continuously enrolled drop out in the following term, while over $65 \%$ are observed enrolled for 5 or more additional terms. Less than $5 \%$ of those classified as dropouts reenroll for 5 or more terms, as compared to about 35\% of those classified as stopouts. These statistics (see Appendix A) suggest that our empirical definition does a reasonable job distinguishing among individuals who enroll for the duration, who interrupt their college experience, and who actually drop out.

The explanatory variables used in our analysis are defined in Table 1. Following the convention of the three major attrition models discussed in the literature review, we include demographic, background, personal, family, institutional, and economic characteristics. Demographic characteristics include gender, race, and ethnicity. Family background is captured with measures of parental education and income in order to capture familial support (both monetary and psychological) for higher education. Personal characteristics, like age and grade point average (GPA), influence both the expected gain from and cost to education as well as the likelihood of graduating. Age is entered as (age -16) so that it takes a value of zero for the youngest first-time enrolled student within the sample. Dummy variables identifying individuals who first enroll in the fall term and who enroll immediately following high school graduation are 
included to proxy for the degree of individual commitment to and interest in higher education. Family characteristics such as marital and parental status may be important, especially for women, as an indication of the household and child rearing opportunity cost of pursuing a degree. We include variables reflecting both initial status for these factors and dummy variables identifying changes ${ }^{2}$ in those factors separately by gender. There are so few men who were divorced/separated/widowed when initially enrolled or whose marital status changed during the course of the first eighteen months, that we are unable to include these men in the study and hence unable to identify the impact such changes have on men's enrollment pattern. ${ }^{3}$ As an interesting observation from the raw data, we note that of the eighteen men who became married within this time frame, none stopped out. However, a larger sample would be necessary to draw any clear inferences about the role of marital changes for men. Institution-specific factors, such as institution type and distance from home are included. ${ }^{4}$ Finally, the economic environment as measured by student aid receipt and alternative employment and wage opportunities may also be important. The latter are likely to be especially critical for older students with higher economic opportunity costs.

Table 2 provides weighted sample means by outcome. Figures at the bottom of the table indicate that approximately $75 \%$ of our sample are enrolled continuously, $10 \%$ stop out, and $15 \%$ drop out. For reasons noted earlier, we believe these estimates may overstate dropout behavior at the expense of stopout behavior. Thus, stopout behavior may be more common than is indicated here. While some differences are apparent in the sample means by outcome, we forego discussion of simple correlations in order to focus on the estimation results that control for all the variables simultaneously. 
MNL Results

Table 3 provides the odds ratios from the multinominal logit model (MNL). All ratios are adjusted for the complex survey design of the BPS-90 (see Thomas and Heck 2001 for a justification). Tests were also conducted to determine whether the assumptions underlying the MNL specification are appropriate. Specifically, we conducted a Hausman test of the maintained assumption of Independence of Irrelevant Alternatives (IIA). If two alternatives are more similar to one another than to the third alternative, as might be supposed if individuals first decide to interrupt and then decide whether the interruption is permanent or temporary, we would expect the test of IIA to reveal such similarities. The fact that we are unable to reject the null hypothesis that the MNL model is appropriate for these data lends further credibility to the use of this specification. $^{5}$

The first two columns in Table 3 report odds ratios and standard errors comparing shortterm stopout with continuous enrollment. Values above one indicate that higher values of the explanatory variable increase the predicted probability of stopout, compared to continuous enrollment. Coefficients less than one indicate the opposite. For example, the risk ratio of 3.37 for students with low GPAs indicates that the relative risk of choosing to stopout as compared to being continuously enrolled is 237 percent higher for those receiving low grades than for those with institution-reported average GPAs. The second two columns report odds ratios and standard errors comparing dropout with continuous enrollment. As before, values above one indicate an increased likelihood, in this case, of dropout behavior, relative to continuous enrollment. The final two columns of the table are derived directly from the data in the first four columns of the table. These columns present the odds ratios and standard errors associated with stopout as compared to dropout activity. In this case, odds ratios above one indicate an increased 
likelihood of long-term dropout behavior as compared to temporary stopout activity. Asterisks identify the individual variables that have statistically significant effects for each set of outcome pairs.

F-tests are used to judge the overall power of these explanatory variables to explain the outcome. The resulting test statistics allow us to reject the hypothesis that all the odds ratios are jointly one, as well as the hypotheses that all the ratios in the first, second, or third set of columns are jointly one. The result for the last test implies that there are significant differences between the factors associated with short-term stopout behavior and the factors associated with long-term dropout behavior. This finding indicates that, contrary to the assumptions implicit in the literature, stopout and dropout behaviors are distinctly different choices.

An analysis of Table 3 indicates that black students are $78 \%$ more likely than whites to stop out relative to enrolling continuously and that nonwhite/nonblacks are only about half as likely as whites to drop out rather than to enroll continuously. Overall, however, demographic characteristics are not jointly significant determinants of enrollment outcome (p-value 0.21 ).

Parental education is a significant determinant of behavior (p-value 0.0015). Students whose parents have completed college (the base case) are significantly more likely to be continuously enrolled than to stop out or to drop out, as compared to students whose parents have less education. However, parental education does not significantly affect (p-value 0.61) dropout as compared to stopout behavior. ${ }^{6}$

Contrary to expectations, household income has no jointly significant effect on enrollment activity (p-value 0.22) and the only income variable to enter with any significance is the one identifying dependent students from very low income households. These students are $78 \%$ more likely than individuals from households with $\$ 30-50,000$ incomes to drop out than to 
continue, even though income was known ex-ante. On the whole, it would appear that whereas income may influence the decision to enroll in college in the first place, it does not play a substantial role in subsequent enrollment decisions.

The timing of college entry is significantly associated with the enrollment outcome overall (the p-value for the test that no timing variables belong in the model at all is 0.0000 ) and helps distinguish between stopout and dropout behavior ( $\mathrm{p}$-value 0.0041). Older men are more likely than younger men to drop out rather than to continue, while age is not a significant factor in the dropout/continue decision for women. This gender differential becomes significant by about age 25. Age effects are, however, difficult to isolate as age is not observed independent of other timing factors. ${ }^{7}$ Those initially entering in the fall term are marginally more likely to enroll continuously than to stop out as compared with those entering in a non-fall term, but jointly the four timing variables have no significant association with stopout behavior (p-value 0.3245). By contrast, three of four timing variables significantly influence the likelihood with which an individual is observed dropping out for the long-term versus enrolling continuously. Those first entering in the fall term and those matriculating immediately after high school are substantially less likely to drop out on a permanent basis than to be continuously enrolled, compared to those first enrolling in a non-fall term or delaying entry to college. Matriculation immediately after high school is further associated with a significantly lower probability of dropping out as compared to stopping out. This result is expected since those students enrolling in the fall term and matriculating immediately after high school are following the lockstep education pattern of high school to college and are in some sense conforming to traditional educational life cycle behavior patterns. It is also likely that these students will have fewer life cycle distractions relative to those who delayed enrollment. 
As expected, the influence of grades is substantial (see Harmston 2004 for further evidence). Those missing all grade reports (perhaps because all courses were taken pass/fail) and those with low grades are over three times more likely to stop out or to drop out than to remain continuously enrolled, as compared to those with institution-reported mid-level grades. Those self-reporting mid-level grades are no more likely to stop out versus remain enrolled continuously than those with institutionally-reported mid-level grades. They do appear, however, to have a higher probability of dropping out relative to continuing and furthermore of dropping out relative to stopping out. We observe no evidence that those with high grades are more likely to stop out in order to transfer between institutions. Such transfers may be more likely to occur between academic years, such that no enrollment gap is observed. Tests interacting income with GPA provided no evidence that independent students or those from less privileged households were more sensitive to grade reports. This would seem to suggest a lack of a "discouraged student" effect that applies differentially to low income relative to higher income students who receive low grades. Low grades apparently send a similar message regardless of income status.

Preexisting family characteristics, such as already being married or already having a child, play a pivotal role in first year enrollment behavior, though one qualified somewhat by the small numbers involved. Current marital status is more significantly correlated with stopout (pvalue 0.0053$)$ than with dropout (0.0382) behavior, but is significant in each comparison. Married men are significantly and substantially more likely to stop out, rather than to enroll continuously as compared to never married men. They are also significantly and substantially more likely to stop out than to drop out as compared to never married men. Indeed being married lowers men’s probability of dropping out. Married women are also more likely to stop 
out than otherwise similar single women, but their probability of dropping out also rises a bit. Already divorced women are more likely to drop out than to continue their education as compared to never married women, but this differential is only marginally significant. Parental status variables are important, too, though the impact of children under age six differs for men and women. The presence of a young child makes women more likely to drop out than to stop out and men more likely to enroll continuously than to drop out as compared to their fellows without children.

Changes in marital and parental status often have a significant impact as well. Women who marry are more likely to drop out but less likely to stop out, relative to remaining continuously enrolled, than women whose marital status does not change. Women whose marriages end are more likely to stop out and less likely to drop out, relative to remaining continuously enrolled, than women whose marital status does not change. Having a newborn substantially increases the odds with which men will drop out rather than either stop out or remain enrolled. Women who have a newborn are somewhat more likely to both drop out and stop out than women who do not, though the association with dropout behavior is stronger.

Institutional characteristics as a whole have a strong impact on interruptions of all sorts. The public/private nature of the institution has no significant or substantial effect. Those individuals attending a two year institution are, however, more likely to both stop out and drop out than those individuals attending a four year institution, approximately doubling both probabilities.

The impact of financial aid receipt is of particular interest to policy makers. Our results indicate that aid does not help differentiate between short-term stopout and continuous enrollment (p-value 0.45$)$. However, the probability of dropping out, relative to stopping out or 
to remaining continuously enrolled, is higher for those receiving loans and lower for those receiving work-study aid as compared to those receiving no aid. Loans must be paid back and may be seen as a drain on future income. Work-study aid, by contrast, may both integrate the student more closely to the college and provide a convenient income source. Work-study schedules are also more likely to mesh with, rather than to interfere with, class schedules.

Finally, while a higher unemployment rate has the predicted positive impact on continuous enrollment, suggesting that higher unemployment rates keep students from leaving school, the unemployment rate is only statistically significant in distinguishing between dropout and continuous enrollment. Overall, the set of economic variables is not statistically significantly related to enrollment outcome (joint p-value across all equations is 0.25 ).

In Table 4, we report the predicted probability of each outcome for individuals with select characteristics. This table provides further information regarding the impact certain factors have on enrollment behavior. The base case, reported in the top row of this table, is that of an 18-year-old, white male who begins college in the fall term immediately following his high school graduation, whose parents have completed college and have an income between $\$ 30,000$ and $\$ 50,000$, who has an average first year GPA, attends a private four-year college that is between 10 and 100 miles from his parent's home, is unmarried and not a parent, lives in an area with a 5.6\% unemployment rate, has standard expected earnings, and does not receive financial aid. Our model predicts that an individual with these characteristics has a $90.2 \%$ probability of being continuously enrolled, a $7.5 \%$ probability of stopping out, and a $2.3 \%$ probability of dropping out. These figures are notable as this stereotypical college student is not one we would expect to stop out, yet the predicted probability of such an individual stopping out is substantially (three times) and significantly (at the $1 \%$ level) greater than the predicted probability of his 
dropping out. Even this basic finding supports the thrust of our research that stopout and dropout behaviors are important and worth examining separately.

Other predicted outcome probabilities are also presented in Table 4. The impact of a low GPA is shown to decrease the probability of continuous enrollment from $90.2 \%$ in the base case to $71.8 \%$. The effect of marriage is also substantial, even taken from a modified base case of an independent 21 year old who has delayed entry to college. Interestingly, the presence of a young child has a moderating influence - increasing the probability of continuous enrollment for both married men and married women. As discussed earlier, individuals receiving grant aid have a somewhat higher probability of continuous enrollment while loans increase the probability of dropping out relative to stopping out and work-study increases the probability of stopping out relative to dropping out, though none of these differences is statistically significant.

Several extensions of this model would be of interest. For example, it would be valuable for policy makers to know whether the results differ between two and four year institutions and between part-time and full-time students. The analysis conducted here restricted the sample to full-time students because of research mentioned earlier that indicates substantial differences in the enrollment patterns of part-time and full-time student. That restriction excludes much of the community college population. When the sample is further restricted to include only students at four year institutions who did not change marital status, the results are quite similar. Our basic finding that stopout and dropout are distinct outcomes is unchanged but differences do arise. For example, parental education appears to be less associated with stopout or dropout for the smaller four-year sample, high grades are associated with less stopout, immediate matriculation reduces stopout, and living nearby increases stopout. The effect of loans and work-study on dropout remain as strong, if not stronger for this smaller sample. A serious problem with such analysis, 
however, is the fact that this is not a random sample. These individuals chose to attend a four year institution and that choice may be correlated with the later withdrawal decision. Further joint analysis of college choice and enrollment patterns is warranted.

A Comparison of the MNL and SL Models

The results of our MNL indicate that there are distinct differences between those who stop out and those who drop out. This suggests that parameter estimates from a standard logit (SL) model of attrition that fails to distinguish between stopout and dropout behavior (for example, Harmston 2004) will be biased. We examine the nature and magnitude of this potential issue by estimating a simple logit model in which dropout and stopout are treated as a single behavior (interrupted enrollment) and contrasted with continuous enrollment. In table 5, we present odds ratios from the MNL model of dropout side-by-side with parameter estimates from the simple logit (SL) analysis. The MNL odds ratios are simply copied from the middle columns of Table 3. Table 5 demonstrates the importance of distinguishing between short-term and longterm withdrawal.

Focusing primarily upon the coefficients that are statistically significant, there are several key differences between the MNL and SL specifications. First, the association between immediate matriculation and dropout behavior is lost in the SL model because those who immediately matriculate are no more likely to stop out than to remain continuously enrolled.

Second, the effect of gender and age is similar between the two models but only after one takes into account the substantially larger probability with which women of any age will drop out in the SL model. Married women, who appear more likely to drop out using the standard definition of attrition, actually appear so inclined not because they drop out for the long term, but 
because they are significantly more likely to stop out for a short time. However, when stopout and dropout are treated as the same behavior, the strong association with stopout behavior dominates and gives the impression that being a married woman increases the probability of becoming a dropout. An advantage of the MNL analysis is that we "see" married women as temporary stopouts rather than as permanent dropouts. Although the traditional literature treats them as dropouts, many married women actually return quickly to higher education i.e. they are really stopouts not dropouts. Conversely, women who marry do not appear significantly more likely to drop out in the simple model, because they are no more likely to stop out. Similarly, men who become fathers do not appear at risk for dropping out using the SL model, because they are so much less likely to stop out than men who do not become fathers but the MNL model shows they are at risk.

Third, grant receipt and 'lives further than 100 miles' are statistically significant in the SL model but not the MNL model. This result can probably be attributed to the fact that each of these variables is associated with an increased probability of continuous as opposed to either dropout or stopout activity in the MNL model, and this increased probability is almost statistically significant. Last, loans and work-study aid do not appear to have a significant influence in the SL model, because such aid does not change the probability of continuous enrollment, only the dropout/stopout mix which does not become apparent until a MNL perspective is adopted.

In summary, using a model of attrition that fails to distinguish between short-term and long-term withdrawal will only accurately identify those factors that have a similar impact on stopout and dropout behavior. Those factors that have a differential impact on stopout and dropout behavior cannot be accurately assessed with a SLmodel that treats the two behaviors as 
if they were the same. One of these effects may dominate, or they may balance or cancel each other out, causing the simple logit on interruptions to yield substantially different results than the more complex MNL model. The MNL model provides a significantly more flexible specification.

\section{Conclusion}

Attrition studies often fail to distinguish between short-term and long-term interruptions and typically assume that all attrition is either permanent or temporary. In truth there is a substantial amount of both types of attrition. Using longitudinal data from the BPS-90, we focus on enrollment during the first year (when most attrition occurs) and define long-term dropouts as individuals who interrupt their studies for more than a calendar year and short-term stopouts as individuals who interrupt their studies for a calendar year or less beginning in the first year. By this definition, $40 \%$ of all first year attrition is temporary.

We use a multinomial logit model to estimate the relation between personal, household, institutional, and economic factors and three first year enrollment outcomes: continuous enrollment, stopout, and dropout. We find significant differences between the factors associated with stopout and dropout behavior. Delayed matriculation, first year financial aid type, and marital and parental status, in particular, generate substantially different predicted interruption types. Furthermore, we show that these differences bias a simple attrition model that fails to distinguish between dropout and stopout behavior.

Our results regarding the impact of student aid on enrollment behavior should be of particular interest to policy makers. A simple logit model of interruptions understates the impact of financial aid receipt on enrollment outcomes. Our analysis shows that those receiving grant, 
work-study, and loan aid during the first year exhibit different enrollment behaviors from one another and from those not receiving aid. Those receiving work-study aid have the lowest probability of dropping out and those receiving grants having the highest probability of enrolling continuously. Further investigation is warranted to determine how changes in and levels of financial aid influence enrollment choices, but initial evidence clearly shows strong support for work-study and grant aid if the goal is persistence towards a degree. Our analysis does not indicate whether those who stop out eventually complete the degree and this issue also warrants further research. If those who stop out simply bounce from program to program and fail to obtain a degree, then distinguishing between stopouts and dropouts may not be particularly valuable from a policy perspective. However, there is evidence (O'Toole, Stratton, and Wetzel 2003) that a surprisingly large fraction of those who interrupt their education are still enrolled five years after initial matriculation, suggesting that these individuals are persisting, just following a nontraditional path to a higher education degree.

The ability to distinguish college students who drop out permanently from those who follow a different path may help policy makers, educators, and even students to make better investment decisions. Students who drop out of school consume taxpayers' dollars and educational resources that could have been used elsewhere. From an individual perspective, students who drop out lose because they do not receive the substantial financial reward, the earnings differential, that college graduates receive. From a social perspective, these individuals fail to repay, in terms of tax revenue, the financial subsidy implicit in the low-cost tuition they may receive from taxpayers. Our results suggest that programs established to aid those at-risk of dropping out will be better targeted when dropout behavior is distinguished from stopout behavior. In addition, identifying those at-risk for stopping out may help institutions and policy 
makers address the needs of this population, and so increase the individual and social returns they generate from higher education. Those individuals who persist towards a degree have the potential to reap returns both for themselves and for society as a whole. This work focuses on

full-time students, but additional work looking at part-time students and at the type of institution attended may improve targeting even more.

The enrollment decision students face is far more complex than the persist/dropout decision typically modeled in the attrition literature. This paper takes a significant step in modeling that behavior, first by demonstrating that a substantial fraction of withdrawals are temporary and second by showing that the factors associated with temporary withdrawals are not the same as those associated with permanent withdrawals. By being able to differentiate stopouts from dropouts, institutions of higher education can more efficiently design intervention plans that address each of these two types of interruptions and so perhaps increase graduation rates and the benefits accruing to both individuals and society. 


\section{Endnotes}

${ }^{1}$ Also excluded were a handful of observations missing family composition data and men whose marital status changed or who were divorced at the time of initial matriculation. The latter two restrictions were imposed due to small sample sizes and/or the fact that none of these men were observed stopping out.

${ }^{2}$ Changes are identified by comparing status just prior to enrollment with status one year and three months later for marriage and with status one year and six months later for parenthood thus permitting some foreknowledge.

${ }^{3}$ This exclusion restriction affects four men who were separated/divorced/widowed, eighteen men who married, and no men whose marriage ends.

${ }^{4}$ Information on the institutional fit is often critical in single institution studies of retention, but less relevant to studies such as this one where respondents may transfer between institutions without being classified as having dropped out. We have tested various measures of academic and social integration, but found they were universally statistically insignificant and so have excluded these variables from the models reported here.

${ }^{5}$ Two Hausman tests were conducted. In one, the MNL results were compared with those from a simple logit between the dropout and continuous samples. In the other one, the MNL results were compared with those from a simple logit between the stopout and continuous samples. In both cases, it was necessary to use a generalized variance-covariance matrix. The p-values associated with the resulting test statistics were 0.93 and 0.96 respectively, allowing us to handily fail to reject the assumption of IIA. 
${ }^{6}$ Parental education appears to have a stronger effect on dropout for students under the age of twenty. As older students are more likely to receive their financial and social support from persons other than their parents, this finding is reasonable, but the difference is not statistically significant.

${ }^{7}$ Specifications with quadratic and nonlinear age effects were tested, but a linear effect appears to be sufficient. 


\section{Acknowledgement}

The data set employed here was generated while working under a grant supported in part by the Association for Institutional Research, the National Center for Education Statistics, and the National Science Foundation under the Association for Institutional Research 1999 Improving Institutional Research in Postsecondary Educational Institutions Grant Program. The analysis was conducted with the funding support of a 2003 Improving Institution Research in Postsecondary Educational Institutions Grant. Any opinions, findings, conclusions, or recommendations expressed in this material are those of the authors and do not necessarily reflect the views of the Association for Institutional Research, the National Center for Education Statistics, or the National Science Foundation. We are grateful to seminar participants at the Århus School of Business (Århus, Denmark), the Virginia Association of Economists, the Virginia Association of Management Analysis and Planning, and referees for helpful comments. 
References

Altonji, J. G. (1993). The demand for and return to education when education outcomes are uncertain. Journal of Labor Economics 11 (1): 48-83.

Bean, J. P. (1980). Dropouts and turnover. The synthesis and test of a causal model of student attrition. Research in Higher Education 12 (2): 155-187.

Brawer, F.B. (1996). Retention-Attrition in the Nineties. Eric Digest, No. ED0-JC-9606.

Braxton, J.M., Sullivan, A. S., \& Johnson, R.M. (1997). Appraising Tinto’s Theory of College Student Departure. Smart, J.C. (Ed.) Higher Education: A Hand Book of Theory and Research. 12, 107-164.

Cabrera, A. F., Castaneda, M.B., Nora, A., \& Hengstler, (1992). The Convergence Between Two Theories of College Persistence. Journal of Higher Education 63 (2): 143-164.

Cameron, S.V. \& Heckman, J.J. (1998). Life cycle schooling and dynamic selection bias: models and evidence for five cohorts of American males. Journal of Labor Economics 106 (2): 262-333.

DesJardins, S.L., Ahlburg, D.A., \& McCall. B.P. (2002). A temporal investigation of factors related to timely degree completion. The Journal of Higher Education 73(5): 555-582.

Hoenack, S.A. \& Pierro, D.J. (1990). An econometric model of a public university's income and enrollment. Journal of Economic Behavior and Organization 14 (3), 403-423.

Harmston, M.T. (2004). Cross-validation of persistence models for incoming freshmen. AIR Professional File 93 (Fall).

Horn, L. (1998). Stopouts or Stayouts? Undergraduates Who Leave College in Their First Year. Washington DC: U.S. Department of Education (NCES 1999-087). 
Kahn, J.H. \& Neuta, M.M. (2001). Social-cognitive predictors of first year college persistence: the importance of proximal assessment. Research in Higher Education 42 (6): 633652.

Light, A. (1996). Hazard model estimates of the decision to reenroll in school. Labour Economics 2: 381-406.

Maddala, G. S. (1994). Limited-Dependent and Qualitative Variables in Econometrics. New York: Cambridge University Press.

Manski, C. F. (1989). Schooling as experimentation: a reappraisal of the postsecondary dropout phenomenon. Economics of Education Review 8 (4): 305-312.

Montmarquette, C., Mahseredjian, S., \& Houle R. (2001). The determinants of university dropouts: a bivariate probability model with sample selection. Economics of Education Review 20: 475-484.

O’Toole, D. M., Stratton, L. S., \& Wetzel, J. N. (2003). A longitudinal analysis of the frequency of part-time enrollment and the persistence of students who enroll part-time. Research in Higher Education. 44(5): 519-537.

St. John, E. P., Cabrera, A. F., Nora, A., \& Asker, E. H. (2000). Economic influences on persistence reconsidered. Braxton, J. M. (Ed.) Reworking the Student Departure Puzzle. Vanderbilt University Press: 29-47.

St. John, E. P. \& Starkey, J. (1995). An alternative to net price assessing the influence of prices and subsidies on within-year persistence. Journal of Higher Education 66(2): 156-186.

St. John, E. P., Hu, S., \& Weber, J. (2001). State policy on the affordability of public higher education: the influence of state grants on persistence in Indiana. Research in Higher Education 42(4): 401-428. 
Thomas, S. L. \& Heck, R.H. (2001). Analysis of large-scale secondary data in higher education research: potential perils associated with complex sampling designs. Research in Higher Education 42(5): 517-540.

Tinto, V. (1975). Dropout from higher education: a theoretical synthesis of recent research. Review of Educational Research 45(1): 89-125.

Weiler, W. \& Pierro, D. (1988). Selection bias and the analysis of persistence of parttime undergraduate students. Research in Higher Education 29(3): 261-272. 


\section{Table 1 $\underline{\text { Variable Definitions }}$}

\section{Demographic Characteristics}

Female

Black

Nonwhite/Nonblack

Hispanic

Parental Education

Less than High School

High School

Some College

College +

Missing

Household Income

Independent

Parental Income $<\$ 20 \mathrm{~K}$

Parental Income $\$ 20-30 \mathrm{~K}$

Parental Income $\$ 30-50 \mathrm{~K}$

Parental Income $>\$ 50 \mathrm{~K}$

$\underline{\text { Timing }}$

First Attended in the Fall Term Immediate Matriculation

Male Age - 16

Female Age - 16

\section{Grades}

Low GPA

Self-Reported Average GPA

Institution-Reported Average GPA High GPA

Missing GPA
1 if Female

1 if Black

1 if neither White nor Black

1 if Hispanic. Note that ethnicity and race are identified separately.

Dummy variables identifying the highest level of education completed by a parent. Use parental reply where available, else respondent's.

1 if most educated parent did not complete high school.

1 if most educated parent completed high school, no more.

1 if most educated parent took some college courses.

1 if most educated parent completed college or more. Base Case. 1 if have no information on parental education from either parent or respondent.

1 if student declares him/herself to be financially independent.

1 if student is dependent and annual parental income is $<\$ 20,000$

1 if student is dependent and annual parental income is $\$ 20-30,000$

1 if student is dependent and annual parental income is $\$ 30-50,000$.

Base Case.

1 if student is dependent and annual parental income is $>\$ 50,000$

1 if first attend during the fall term.

1 if individual matriculated immediately after completing high school.

Age - 16 for Men

Age - 16 for Women

First year GPA with preference given to institution-reported grades. Institution reports GPA $<2.0$ or individual reports "Mostly C's" or worse. Individual reports "Mostly B's" or "B's and C's". No institution report available.

Institution reports GPA between 2.0 and 3.25. Base Case. Institution reports GPA > 3.25 or individual reports "A's and B's" or better.

Neither institution nor individual reported first year grades. 
Family Characteristics

Current Marital Status

Married Man

Married Woman

Sep/Div/Wid Woman

Change in Marital Status

Woman who Marries

Woman whose Marriage Ends

Current Parental Status

Male Parent, Child < Age 6

Female Parent, Child $<$ Age 6

Change in Parental Status

Child Born to Man

Child Born to Woman

Institutional Characteristics

Public School

Two Year School

Lives within 10 miles

Lives 10-100 miles away

Lives further than 100 miles

$\underline{\text { Financial Aid Variables }}$

Received a Grant

Received a Loan

Received Work-Study

Received Employer Provided Aid

Received Other Aid

\section{Economic Conditions}

1990 Unemployment Rate

Expected Earnings (in 000s)
Measured at the start of the first term enrolled.

1 if respondent is a married man.

1 if respondent is a married woman.

1 if respondent is a separated, divorced, or widowed woman.

Measured at the end of the term that begins one calendar year after first enrolled.

1 if respondent is a woman who marries.

1 if respondent is a woman whose marriage ends.

Measured before initial enrollment.

1 if the respondent is a man with a child born after 1981.

1 if the respondent is a woman with a child born after 1981.

Measured 18 months after first enrolled.

1 if the respondent is a man and a child enters his household.

1 if the respondent is a woman and a child enters her household.

For first school attended.

1 if institution is Public, 0 if Private.

1 if institution is a 2 year school, 0 if a 4 year school.

1 if respondent lives within 10 miles of institution.

1 if respondent lives 10 to 100 miles away from institution. Base Case.

1 if respondent lives more than 100 miles away from institution.

Dummy variables identifying the type of financial aid the individual

received in his/her first year.

1 if respondent received a grant.

1 if respondent received a loan.

1 if respondent received work-study aid.

1 if respondent received employer provided aid.

1 if respondent received other aid.

1990 Unemployment Rate in respondent's home state.

1990 Census data reporting earnings of a high school graduate working full-time, matched to the respondent's gender, race/ethnicity, and age. 


\section{Table 2 \\ Sample Means by Enrollment Outcome}

\section{Variable}

Demographic Characteristics

Female

Black

Nonwhite/Nonblack

Hispanic

Parental Education

Less than High School

High School

Some College

College + (Base Case)

Missing

Household Income

Independent

Parental Income $<\$ 20 \mathrm{~K}$

Parental Income $\$ 20-30 \mathrm{~K}$

Parental Income $\$ 30-50 K \quad$ (Base Case)

Parental Income $>\$ 50 \mathrm{~K}$

Timing

First Attended in the Fall Term

Immediate Matriculation

Male Age - 16

Female Age - 16

Grades

Low GPA

Self-Reported Average GPA

Institution-Reported Average GPA

(Base Case)

High GPA

Missing GPA

Family Characteristics

Married Man

Married Woman

Sep/Div/Wid Woman

Woman who Marries

Woman whose Marriage Ends

Male Parent

Female Parent

Male Parent, Child < Age 6

Female Parent, Child < Age 6

Child Born to Man

Child Born to Woman
Continuously

Enrolled

Mean Std Err

$0.5418 \quad 0.0126$

$0.0702 \quad 0.0076$

$\begin{array}{ll}0.0668 & 0.0077\end{array}$

$0.0566 \quad 0.0067$

$\begin{array}{ll}0.0443 & 0.0059\end{array}$

$0.2577 \quad 0.0120$

$0.2235 \quad 0.0104$

$\begin{array}{ll}0.4649 & 0.0137\end{array}$

$0.0096 \quad 0.0030$

$0.0730 \quad 0.0081$

$\begin{array}{ll}0.1610 & 0.0089\end{array}$

$0.2801 \quad 0.0114$

$0.2372 \quad 0.0110$

0.2486

0.0103

$0.9519 \quad 0.0095$

0.9027

1.2240

1.5890

0.0082

0.0602

0.0911

0.1634

0.0109

$0.0867 \quad 0.0104$

$0.4338 \quad 0.0154$

$0.3113 \quad 0.0119$

$0.0049 \quad 0.0017$

\begin{tabular}{ll}
$0.0081 \quad 0.0022$ \\
\hline
\end{tabular}

$\begin{array}{ll}0.0181 & 0.0039\end{array}$

0.0046

0.0071

0.0032

0.0104

0.0257

0.0074

0.0133

0.0032

0.0069
Stopout

Mean Std Err

$0.5005 \quad 0.0445$

$0.1349 \quad 0.0310$

$\begin{array}{ll}0.0410 & 0.0212\end{array}$

$0.0428 \quad 0.0147$

$0.0370 \quad 0.0134$

$\begin{array}{ll}0.3105 & 0.0367\end{array}$

$0.2646 \quad 0.0340$

$\begin{array}{ll}0.3494 & 0.0371\end{array}$

$0.0385 \quad 0.0175$

$\begin{array}{lll}0.1328 & 0.0281\end{array}$

$\begin{array}{ll}0.1847 & 0.0342\end{array}$

$0.2283 \quad 0.0326$

$0.2218 \quad 0.0304$

$0.2325 \quad 0.0351$

$\begin{array}{ll}0.8923 & 0.0314\end{array}$

$0.8358 \quad 0.0282$

$\begin{array}{ll}1.4282 & 0.1420\end{array}$

$1.8732 \quad 0.4252$

$0.3941 \quad 0.0427$

$0.0585 \quad 0.0165$

$0.3115 \quad 0.0340$

$0.2170 \quad 0.0365$

0.0189

0.0142

\begin{tabular}{ll}
$0.0188 \quad 0.0080$ \\
\hline
\end{tabular}

$0.0462 \quad 0.0193$

$\begin{array}{ll}0.0075 & 0.0067\end{array}$

$0.0062 \quad 0.0040$

$0.0098 \quad 0.0098$

$0.0097 \quad 0.0060$

$\begin{array}{ll}0.0490 & 0.0201\end{array}$

$0.0088 \quad 0.0059$

$\begin{array}{ll}0.0057 & 0.0035\end{array}$

$0.0012 \quad 0.0012$

$0.0129 \quad 0.0051$
Dropout

Mean Std Err

$0.5352 \quad 0.0345$

$0.1150 \quad 0.0226$

$\begin{array}{ll}0.0293 & 0.0107\end{array}$

$0.0741 \quad 0.0235$

$0.1042 \quad 0.0250$

$\begin{array}{ll}0.3463 & 0.0314\end{array}$

$0.2632 \quad 0.0316$

$0.2604 \quad 0.0320$

$0.0259 \quad 0.0098$

$\begin{array}{ll}0.2053 & 0.0292\end{array}$

$\begin{array}{ll}0.2084 & 0.0279\end{array}$

$\begin{array}{lll}0.2593 & 0.0298\end{array}$

$\begin{array}{ll}0.1134 & 0.0197\end{array}$

$\begin{array}{ll}0.2137 & 0.0267\end{array}$

$\begin{array}{ll}0.8213 & 0.0345\end{array}$

$\begin{array}{ll}0.6631 & 0.0342\end{array}$

$\begin{array}{ll}1.8828 & 0.3794\end{array}$

$2.4180 \quad 0.3191$

$0.3848 \quad 0.0355$

$0.1218 \quad 0.0233$

$\begin{array}{ll}0.2654 & 0.0301\end{array}$

$0.1632 \quad 0.0287$

$0.0647 \quad 0.0235$

$\begin{array}{ll}0.0174 & 0.0092\end{array}$

$0.0591 \quad 0.0200$

$0.0439 \quad 0.0140$

$0.0296 \quad 0.0076$

$0.0009 \quad 0.0009$

$0.0172 \quad 0.0096$

$0.1237 \quad 0.0261$

$0.0035 \quad 0.0025$

$0.1078 \quad 0.0290$

$\begin{array}{ll}0.0179 & 0.0095\end{array}$

$0.0588 \quad 0.0171$ 


\author{
Institutional Characteristics \\ Public School \\ Two Year School \\ Lives within 10 miles \\ Lives 10-100 miles away (Base Case) \\ Lives further than 100 miles \\ Financial Aid \\ Received a Grant \\ Received a Loan \\ Received Work-Study \\ Received Employer Provided Aid \\ Received Other Aid \\ Economic Factors \\ 1990 Unemployment Rate \\ Expected Earnings (in 000s) \\ \# of Observations \\ Weighted Fraction of Sample
}

3461

$\begin{array}{rrrrrr}0.7416 & 0.0147 & 0.8215 & 0.0235 & 0.8462 & 0.0189 \\ 0.3177 & 0.0195 & 0.5259 & 0.0428 & 0.6585 & 0.0349 \\ 0.2561 & 0.0152 & 0.3057 & 0.0392 & 0.4595 & 0.0343 \\ 0.4349 & 0.0145 & 0.5017 & 0.0412 & 0.4218 & 0.0339 \\ 0.3090 & 0.0151 & 0.1927 & 0.0266 & 0.1187 & 0.0171 \\ & & & & & \\ 0.4424 & 0.0138 & 0.3231 & 0.0331 & 0.3473 & 0.0331 \\ 0.2189 & 0.0097 & 0.1566 & 0.0209 & 0.2015 & 0.0235 \\ 0.1016 & 0.0075 & 0.0729 & 0.0135 & 0.0508 & 0.0120 \\ 0.0043 & 0.0012 & 0.0099 & 0.0092 & 0.0031 & 0.0022 \\ 0.1507 & 0.0095 & 0.0968 & 0.0250 & 0.0729 & 0.0144 \\ & & & & & \\ 5.5729 & 0.0419 & 5.5192 & 0.0796 & 5.5134 & 0.0610 \\ 14.9277 & 0.0568 & 15.0888 & 0.1592 & 15.2690 & 0.1754 \\ & & & & & \\ 3461 & & 343 & & 422 & \\ 75.2 \% & & 10.1 \% & & 14.7 \% & \end{array}$




\section{Table 3}

\section{Multinomial Logit Model of Continuous, Stopout, and Dropout Behavior}

\section{Demographic Characteristics}

Variable

\begin{abstract}
Female
\end{abstract}
Black

Nonwhite/Nonblack

Hispanic

Parental Education

Less than High School

High School

Some College

Missing

Household Income

Independent

Parental Income $<\$ 20 \mathrm{~K}$

Parental Income $\$ 20-30 \mathrm{~K}$

Parental Income $>\$ 50 \mathrm{~K}$

Timing

First Attended in the Fall Term

Immediate Matriculation

Male Age - 16

Female Age - 16

Grades

Low GPA

Self-Reported Average GPA

High GPA

Missing GPA

Family Characteristics

Married Man

Married Woman

Sep/Div/Wid Woman

Woman who Marries

Woman whose Marriage Ends

Male Parent, Child < Age 6

Female Parent, Child < Age 6

Child Born to Man

Child Born to Woman
Stopout versus

Continuous

$\underline{\text { Odds Ratio Std Error }}$

0.6037

1.7829

0.5592

0.8068

0.2652

0.5800 *

0.3387

0.2856

0.8279

1.7053

1.5929

5.9235

1.2691

1.0697

0.6813

0.8790

0.4527

0.3963 **

0.3509 **

$3.6234 * * *$

0.5026

0.7254

0.9599

0.9554

0.5976

0.3754

0.1741

0.2137

0.1933 *

0.2297

0.0903

0.0607

3.3680

0.7296

0.8865

3.8601

0.6694 ***

0.2489

0.2139

3.0356 *

11.6366

4.0644

3.2755

0.9853

1.9488

0.4708

0.1495

0.0653

1.5428

$9.2965 * \star *$

2.5946 **

3.9894

0.7846

2.4087

0.2534

0.1345 **

0.0792 **

0.9812
Dropout versus
Continuous

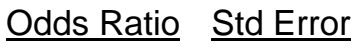

$0.7494 \quad 0.2773$

$1.0925 \quad 0.3161$

$0.3564 \quad 0.1939$

$0.7646 \quad 0.3596$

$1.6631 \quad 0.6556$

2.00790 .4334 ***

1.73290 .4075 **

$4.4158 \quad 2.3644^{* * *}$

1.1127

0.4487

1.7823

0.5625 *

1.1730

0.3488

1.4632

0.3730

0.3360

$0.1162 * * *$

0.3385

1.1259

$0.0925 * * *$

0.0612 **

$0.9851 \quad 0.0381$
$0.9342 * * *$

0.6353 **

0.2150

7.2464 ***

$0.5569 \quad 0.5140$

$1.9221 \quad 1.2041$

5.2555

3.4517

0.1934

0.2164

2.0475

5.1070

7.2007
4.8774 *

$2.0720 * *$

0.2115

0.1700

1.0964

3.7838 **

3.4709 ***
Dropout versus

Stopout

Odds Ratio Std Error

$\begin{array}{ll}1.2412 & 0.5637 \\ 0.6128 & 0.2473 \\ 0.6373 & 0.4329 \\ 0.9476 & 0.5145\end{array}$

$2.0089 \quad 1.1999$

$1.1774 \quad 0.3254$

$1.0879 \quad 0.3145$

$0.7455 \quad 0.4962$

$0.8768 \quad 0.4464$

$1.6661 \quad 0.7518$

$1.7218 \quad 0.6195$

$1.6646 \quad 0.5555$

$0.6686 \quad 0.2457$

$0.4666 \quad 0.1681$

$1.1729 \quad 0.1207$

$1.0311 \quad 0.0599$

$1.3061 \quad 0.3053$

$2.7090 \quad 1.0964$ **

$0.9288 \quad 0.3222$

$3.8495 \quad 3.2315$

0.04790 .0511 ***

$0.4729 \quad 0.3308$

$1.6045 \quad 1.8257$

$3.5033 \quad 2.8873$

$0.0992 \quad 0.1486$

$0.4596 \quad 0.3635$

$13.6942 \quad 13.6225$ ***

78.1993101 .9543 ***

4.66723 .1114 ** 
Institutional Characteristics

\begin{tabular}{|c|c|c|c|c|c|c|c|}
\hline Public School & 0.9148 & 0.1631 & 1.0417 & 0.1953 & & 1.1387 & 0.2863 \\
\hline Two Year School & 2.0354 & $0.3768 * \star \star *$ & 2.5878 & 0.4340 & *** & 1.2714 & 0.2713 \\
\hline Lives within 10 miles & 0.8826 & 0.1949 & 1.3526 & 0.2562 & & 1.5325 & 0.4027 \\
\hline $\begin{array}{l}\text { Lives further than } 100 \text { miles } \\
\text { lancial Aid }\end{array}$ & 0.7635 & 0.1420 & 0.7886 & 0.1563 & & 1.0329 & 0.2586 \\
\hline Received a Grant & 0.7161 & 0.1621 & 0.7640 & 0.1645 & & 1.0668 & 0.2943 \\
\hline Received a Loan & 0.8590 & 0.1683 & 1.4308 & 0.2965 & * & 1.6657 & 0.4427 \\
\hline $\begin{array}{l}\text { Received Work-Study } \\
\text { Received Employer Provided }\end{array}$ & 1.0703 & 0.2779 & 0.4741 & 0.1712 & ** & 0.4430 & 0.1855 \\
\hline $\mid$ & 2.9100 & 3.1794 & 0.9172 & 0.7195 & & 0.3152 & 0.4064 \\
\hline $\begin{array}{l}\text { Received Other Aid } \\
\text { onomic Factors }\end{array}$ & 0.9540 & 0.2902 & 0.8909 & 0.2285 & & 0.9338 & 0.3484 \\
\hline 1990 Unemployment Rate & 0.8911 & 0.0902 & 0.8459 & 0.0856 & * & 0.9492 & 0.1211 \\
\hline Expected Earnings (in 000s) & 0.8921 & 0.1214 & 0.8626 & 0.0934 & & 0.9669 & 0.1471 \\
\hline Cest All & 6.79 & & & & & & \\
\hline Test Column & 3.83 & & 10.03 & & & 2.67 & \\
\hline
\end{tabular}

Asterisks indicate statistical significance using a 2-tailed test. ${ }^{\star \star \star}$ indicates significance at the $1 \%$ level, ${ }^{\star \star}$ at the $5 \%$ level, and * at the $10 \%$ level.

All statistics take into account the complex sample design of the BPS. 


\section{Table 4 \\ Selected Predicted Outcome Probabilities}

\section{Individual Characteristics}

\author{
Base Case (a) \\ Woman \\ Parents have only a High School Education \\ Delayed Entry \\ First Attending a Non Fall Term \\ Low GPA \\ Age 21, Independent, Delayed Entry

$$
+ \text { Married + Child < Age } 6
$$$$
+ \text { Married }
$$ \\ Woman, Age 21, Independent, Delayed Entry \\ + Married \\ + Married + Child < Age 6 \\ Public School \\ Two-Year School \\ Received a Grant \\ Received a Loan \\ Received Work-Study
}

\author{
Continuous \\ Enrollment \\ Stopout \\ Dropout \\ Behavior \\ Behavior
}

\begin{tabular}{|c|c|c|c|}
\hline $90.2 \%$ & $7.5 \%$ & $2.3 \%$ & $\star \star \star *$ \\
\hline $91.4 \%$ & $6.5 \%$ & $2.1 \%$ & \\
\hline $83.8 \%$ & $11.9 \%$ & $4.3 \%$ & $\star \star$ \\
\hline $84.0 \%$ & $9.6 \%$ & $6.4 \%$ & \\
\hline $80.6 \%$ & $13.3 \%$ & $6.1 \%$ & \\
\hline $71.8 \%$ & $20.1 \%$ & $8.1 \%$ & $\star * a$ \\
\hline $80.1 \%$ & $10.3 \%$ & $9.6 \%$ & C \\
\hline $39.1 \%$ & $58.3 \%$ & $2.6 \%$ & $\star * * a$ \\
\hline $58.2 \%$ & $40.9 \%$ & $0.8 \%$ & * \\
\hline $84.7 \%$ & $9.1 \%$ & $6.2 \%$ & \\
\hline $63.3 \%$ & $27.8 \%$ & $8.9 \%$ & C \\
\hline $73.9 \%$ & $4.8 \%$ & $21.2 \%$ & \\
\hline $90.7 \%$ & $6.9 \%$ & $2.4 \%$ & $\star \star \star ~$ \\
\hline $81.0 \%$ & $13.7 \%$ & $5.4 \%$ & ** b \\
\hline $92.7 \%$ & $5.5 \%$ & $1.8 \%$ & *夫 \\
\hline $90.3 \%$ & $6.4 \%$ & $3.3 \%$ & \\
\hline $90.8 \%$ & $8.1 \%$ & $1.1 \%$ & *夫 \\
\hline
\end{tabular}

(a) 18-year-old white male who enrolls in the fall term immediately following high school graduation, whose parents have completed college and earn between $\$ 30,000$ and $\$ 50,000$ annually, who has an average GPA, attends a private 4-year college that is 10-100 miles from his parent's home, is unmarried and not a parent, lives in an area with a 5.6\% unemployment rate and has standard expected earnings for an 18 year old white male.

Asterisks indicate whether the predicted probability of dropout is statistically significantly different from the predicted probability of stopout. ${ }^{* *}$ indicates significance at the $1 \%$ level, ${ }^{* *}$ at the $5 \%$ level, and ${ }^{*}$ at the $10 \%$ level.

Letters indicate whether any of the predicted probabilities associated with the row-specific characteristics are significantly different from the predicted probabilities for the Base Case. a indicates a significant differential at the $1 \%$ level, b at the $5 \%$ level, and c at the $10 \%$ level. 


\section{Table 5 \\ Comparing MNL and SL Models of Dropout Behavior}

\begin{tabular}{|c|c|c|c|c|c|c|}
\hline \multirow[b]{2}{*}{ Variable } & \multicolumn{3}{|c|}{$\begin{array}{c}\text { Dropout vs. Continuous } \\
\text { MNL Model }\end{array}$} & \multicolumn{2}{|c|}{$\begin{array}{l}\text { Interrupt vs. Continuous } \\
\text { SL Model }\end{array}$} & \\
\hline & $\underline{\text { Odds Ratio }}$ & $\underline{\text { Std Error }}$ & & $\underline{\text { Odds Ratio }}$ & Std Error & \\
\hline \multicolumn{7}{|l|}{ Demographic Characteristics } \\
\hline Female & 0.7494 & 0.2773 & & 0.6709 & 0.2365 & \\
\hline Black & 1.0925 & 0.3161 & & 1.3277 & 0.3072 & \\
\hline Nonwhite/Nonblack & 0.3564 & 0.1939 & * & 0.4462 & 0.2131 & * \\
\hline Hispanic & 0.7646 & 0.3596 & & 0.8139 & 0.2651 & \\
\hline \multicolumn{7}{|l|}{ Parental Education } \\
\hline Less than High School & 1.6631 & 0.6556 & & 1.3276 & 0.4744 & \\
\hline High School & 2.0079 & 0.4334 & $\star \star \star *$ & 1.8660 & 0.3263 & *** \\
\hline Some College & 1.7329 & 0.4075 & $\star \star$ & 1.6658 & 0.2953 & $\star \star \star ~$ \\
\hline Missing & 4.4158 & 2.3644 & $\star \star \star *$ & 4.9200 & 2.2525 & $\star \star \star *$ \\
\hline \multicolumn{7}{|l|}{ Household Income } \\
\hline Independent & 1.1127 & 0.4487 & & 1.1335 & 0.4046 & \\
\hline Parental Income $<\$ 20 \mathrm{~K}$ & 1.7823 & 0.5625 & * & 1.3574 & 0.3261 & \\
\hline Parental Income $\$ 20-30 \mathrm{~K}$ & 1.1730 & 0.3488 & & 0.8760 & 0.1830 & \\
\hline Parental Income $>\$ 50 \mathrm{~K}$ & 1.4632 & 0.3730 & & 1.1008 & 0.2046 & \\
\hline \multicolumn{7}{|l|}{ Timing } \\
\hline First Attended in the Fall Term & 0.3360 & 0.1162 & $\star \star \star ~$ & 0.4096 & 0.1261 & $\star \star \star *$ \\
\hline Immediate Matriculation & 0.3385 & 0.0925 & 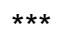 & 0.9786 & 0.0404 & \\
\hline Male Age - 16 & 1.1259 & 0.0612 & $\star *$ & 1.0733 & 0.0518 & \\
\hline Female Age - 16 & 0.9851 & 0.0381 & & 0.4609 & 0.1055 & $\star \star \star ~$ \\
\hline \multicolumn{7}{|l|}{ Grades } \\
\hline Low GPA & 4.3988 & 0.9342 & $\star \star \star *$ & 3.8448 & 0.6464 & 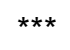 \\
\hline Self-Reported Average GPA & 1.9764 & 0.6353 & $\star \star$ & 1.3636 & 0.3458 & \\
\hline High GPA & 0.8233 & 0.2150 & & 0.8594 & 0.1570 & \\
\hline Missing GPA & 14.8594 & 7.2464 & 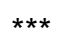 & 8.9518 & 3.9143 & 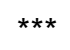 \\
\hline \multicolumn{7}{|l|}{ Family Characteristics } \\
\hline Married Man & 0.5569 & 0.5140 & & 2.2924 & 1.6199 & \\
\hline Married Woman & 1.9221 & 1.2041 & & 2.3794 & 1.2147 & * \\
\hline Sep/Div/Wid Woman & 5.2555 & 4.8774 & * & 4.8083 & 3.9827 & * \\
\hline Woman who Marries & 3.4517 & 2.0720 & $\star \star$ & 2.3475 & 1.2288 & \\
\hline Woman whose Marriage Ends & 0.1934 & 0.2115 & & 0.8430 & 0.8912 & \\
\hline Male Parent, Child < Age 6 & 0.2164 & 0.1700 & * & 0.3141 & 0.1888 & * \\
\hline Female Parent, Child < Age 6 & 2.0475 & 1.0964 & & 1.2649 & 0.5211 & \\
\hline Child Born to Man & 5.1070 & 3.7838 & $\star *$ & 1.6587 & 1.0127 & \\
\hline Child Born to Woman & 7.2007 & 3.4709 & *** & 4.5627 & 1.8710 & 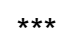 \\
\hline
\end{tabular}




\begin{tabular}{|c|c|c|c|c|c|c|}
\hline Institutional Characteristics & & & & & & \\
\hline Public School & 1.0417 & 0.1953 & & 0.9714 & 0.1274 & \\
\hline Two Year School & 2.5878 & 0.4340 & 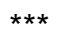 & 2.2833 & 0.3166 & $\star \star \star *$ \\
\hline Lives within 10 miles & 1.3526 & 0.2562 & & 1.1284 & 0.1741 & \\
\hline Lives further than 100 miles & 0.7886 & 0.1563 & & 0.7842 & 0.1146 & * \\
\hline Financial Aid & & & & & & \\
\hline Received a Grant & 0.7640 & 0.1645 & & 0.7360 & 0.1254 & * \\
\hline Received a Loan & 1.4308 & 0.2965 & * & 1.1463 & 0.1731 & \\
\hline Received Work-Study & 0.4741 & 0.1712 & ** & 0.6984 & 0.1576 & \\
\hline Received Employer Provided Aid & 0.9172 & 0.7195 & & 1.7073 & 1.3814 & \\
\hline Received Other Aid & 0.8909 & 0.2285 & & 0.9160 & 0.1971 & \\
\hline Economic Factors & & & & & & \\
\hline 1990 Unemployment Rate & 0.8459 & 0.0856 & * & 0.8656 & 0.0679 & * \\
\hline Expected Earnings (in 000s) & 0.8626 & 0.0934 & & 0.8629 & 0.0837 & \\
\hline F-Test Column & 10.03 & & & 9.64 & & \\
\hline
\end{tabular}

Asterisks indicate statistical significance using a 2-tailed test. ${ }^{\star * \star}$ indicates significance at the $1 \%$ level, ** at the $5 \%$ level, and * at the $10 \%$ level.

All statistics take into account the complex sample design of the BPS. 
Appendix A

\section{Robustness Checks on the Dependent Variable}

\begin{tabular}{|c|c|c|c|c|}
\hline Classification Type & $\begin{array}{c}\% \text { Enrolled } \\
1 \text { Year } \\
\text { following entry }\end{array}$ & $\begin{array}{c}\text { \% Enrolled } \\
\text { only } 1 \text { Term in } \\
\text { Year } 1\end{array}$ & $\begin{array}{c}\% \text { Not } \\
\text { Enrolled later } \\
\end{array}$ & $\begin{array}{c}\text { \% Enrolled for } \\
\text { 5+ Additional } \\
\text { Terms }\end{array}$ \\
\hline Continuous Enrollment & $100.0 \%$ & $0.0 \%$ & $2.5 \%$ & $66.9 \%$ \\
\hline Stopout Behavior & $23.9 \%$ & $22.6 \%$ & $13.6 \%$ & $34.7 \%$ \\
\hline Dropout Behavior & $0.0 \%$ & $30.1 \%$ & $75.3 \%$ & $4.5 \%$ \\
\hline
\end{tabular}


1 